Article

\title{
Studies on Seismic Performance of Precast Concrete Columns with Grouted Splice Sleeve
}

\author{
Zheng Lu, Zixin Wang, Jianbao Li * and Biao Huang \\ Research Institute of Structural Engineering and Disaster Reduction, Tongji University, Shanghai 200092, China; \\ luzheng111@tongji.edu.cn (Z.L.); wzx@tongji.edu.cn (Z.W.); 1630606@tongji.edu.cn (B.H.) \\ * Correspondence: lijianbao@tongji.edu.cn; Tel.: +86-21-6598-6186; Fax: +86-21-6598-2668
}

Academic Editor: Jorge de Brito

Received: 29 March 2017; Accepted: 29 May 2017; Published: 2 June 2017

\begin{abstract}
In order to validate the seismic performance of precast concrete members with steel sleeve connections, pseudo-static tests on four prefabricated columns with vertical grouted splice sleeve connections and on a control group of two cast-in-situ columns have been conducted. The test results indicated that the failure modes of the prefabricated columns and of the cast-in-situ columns are basically identical but differences exist in their crack distribution. The cast-in-situ columns mainly crack horizontally at the bottom of the column, whereas the prefabricated columns have horizontal cracks above the sleeves, and then form diagonal cracks downwards and develop many wider cracks within the range of height of $300 \mathrm{~mm}$ at the bottom of the column. The hysteresis curves of the prefabricated columns are plump, which demonstrates that prefabricated columns have satisfactory energy-dissipating capacity. Moreover, the stiffness degradation of the prefabricated specimens is slower than that of the cast-in-situ specimens. The ultimate displacement angle of the prefabricated columns is up to $1 / 104-1 / 54$, which satisfies the requirements of the inter-story drift ratio during major earthquakes. Finally, some recommendations on practical seismic design pertinent to the precast concrete members with grouted splice sleeves are proposed.
\end{abstract}

Keywords: construction industrialization; zero-carbon building; precast concrete column; grouted splice sleeve; pseudo-static test; low cyclic repeated loading test

\section{Introduction}

Precast concrete construction, as a sustainable technology, not only has the advantages of accelerated construction speed, stable and reliable quality, environmental protection, and savings in material, energy, and labor, but also can shorten the development and construction period of residential and non-residential buildings, which is adapted to large-scale and standardized productions [1-3]. Incorporated with advanced structural control strategies [4-11], precast concrete structures can perform very well under extreme loads [12-15]. As the predominant structural type of construction industrialization in China, precast concrete structures take up $77.1 \%$ of the total floor area built by construction industrialization [16].

It is widely believed that climate change and global warming are closely associated with carbon emissions, and there is a growing concern about the upward trend in greenhouse gas emissions resulting from building construction [17]. It has been verified that buildings worldwide account for one-third of the global carbon emissions [18], and the residential sector accounts for $17 \%$ [19]. To alleviate this situation, it is highly recommended to adopt precast concrete construction. It has been found that the cast-in-situ concrete construction can release $770 \mathrm{~kg}$ of carbon dioxide equivalent per cubic meter of concrete, whereas that is $692 \mathrm{~kg}$ for precast concrete construction, $10 \%$ lower than that of cast-in-situ concrete construction [20]. Based on the specific mix proportion and curing condition, precast concrete under the marine environment can also contribute to a significant 
reduction in carbon emissions [21]. Since precast concrete construction has been proven to be a more environmentally-friendly and energy-efficient method than cast-in-situ construction, it will play an important role during the development of zero-carbon buildings.

The prime issue of the precast concrete structure is the connection between precast components such as beams, columns, slabs and shear walls, etc., that must effectively integrate the individual components to ensure structural safety, serviceability, and durability under various kinds of load conditions [22]. The methods of reinforcement connections for cast-in-situ reinforced concrete structures mainly include bound connections, welded connections, mechanical connections, etc. However, there are some limitations in applying these methods to reinforcement connection of precast members. For example, the mechanical connection requires high installation accuracy of the steel bars, increasing the difficulty of lifting on site. Moreover, since the steel bars are heated during the process of the welded connection, residual stress will be generated in the steel bars. Additionally, due to the small space that the joint of the precast concrete structure occupies, using these conventional reinforcement connection methods would be inconvenient for construction on site. Consequently, reinforcement connection between precast members tends to be one of the critical problems during precast concrete construction.

To solve this problem, Yee [23] firstly proposed the grouted splice sleeve (GSS) in the late 1960s, i.e., the ribbed bars were inserted into the metal sleeve, then the grout was poured, and they could work together after the grout was congealed and hardened. Because of the confinement effect exerted by the sleeve, the bond strength of steel bars enhanced significantly, resulting in a shorter bar embedded length [24]. Afterwards, Alfred A. Yee employed this technology to connect the frame columns of Ala Moana which is a 38-story hotel located in Honolulu. In 1983, the grouted splice sleeve was rated as one of the main reinforcement connection technologies by the American Concrete Institute [25]. The long-term use of this reinforcement connection technology has been tested by earthquakes in many countries, such as the United States and Japan, proving that it can be used in seismic and high-rise buildings.

Regarding the grouted splice sleeve technology, scholars carried out a lot of research work, trying to find the influence factors that dominate the bond performance of the sleeve as well as their influence rules, which can provide the theoretical foundation for sleeve design. For example, Einea et al. [26] utilized the plain round bars to design four types of grouted sleeves with different parameters and geometries, and based on the axial tension test of these specimens, they found that it is practicable to employ the grouted splice sleeve to connect prefabricated members. Ling et al. [27] conducted the tensile tests of two kinds of grouted splice sleeves, namely welded bar sleeve (WBS) and tapered head sleeve (THS), to study the effect of steel bar embedment lengths and sleeve diameters on the tension capacity of sleeves. Sayadi et al. [28] investigated the relationship between the interlocking mechanism and bond strength in both the elastic and inelastic regions of the grouted splice sleeve by experiments, and drew a conclusion that the bond strength will be increased if the interlocking mechanism is arranged at the elastic region. Moreover, some researchers put forward the novel grouted splice sleeve. For example, Seo et al. [29] proposed the grout-filled head-splice-sleeve (HSS) and studied the effect of the configuration with or without the head and head size on the bond behavior via experiments. They found that the configuration with a properly sized head can significantly improve the bond strength and the ductility, leading to steel bars' failure at the end. Furthermore, Henin et al. [30] presented a non-proprietary grouted splice sleeve. Compared to the existing products, this kind of sleeve is preferable with low cost and convenient fabrication, and can be compatible with the current production tolerances.

In order to strengthen the connection performance of traditional grouted splice sleeves, a series of improvement measures have been taken by researchers. For example, based on the cylindrical steel pipe splice, adding spiral reinforcement [31] and bolts [28], and employing tapered steel pipes [32] and square hollow sections [24] can enhance the confinement pressure and bond stress. Additionally, 
to improve the durability and corrosion resistance, some scholars adopted aluminum [33] and glass fiber-reinforced polymer [34,35] instead of steel as the material for making the sleeve.

Although there are many studies on grouted splice sleeve technology, the development of reliable connections which have good force-transferring mechanisms and that are easy for construction is still a hot topic in construction industrialization and zero-carbon buildings. This paper studies a grouted splice sleeve which is very convenient for construction. The seismic performance of precast concrete columns using such a connection method is thoroughly experimentally investigated. The grouted splice sleeve connection studied in this paper for steel bars embedded in prefabricated members is shown in Figure 1a. The precast concrete column has a pre-embedded cast iron sleeve in its lower end and the vertical steel bars of the precast concrete column are inserted into the sleeve. During field installation, the steel bars extended from the pedestal are also inserted into the sleeve; then, the grouting material is poured into the sleeve. After the grout becomes congealed and hardened, the stress of the steel bars is transferred by the bond force between the rebar surface and mortar, as well as between the mortar and sleeve wall. Compared with the traditional methods of reinforcement connection, there is no external force and heat exerted on the rebar, which can prevent the rebar from expansion deformation and residual stress. Additionally, the construction operation is convenient, and the requirements on the construction precision, the quality of the construction workers, and the construction environment are not too high. The proposed bar splice sleeve is tested to be pulled out, showing a failure mode of rebar outside the sleeve yielding and then being ruptured, which meets the requirements. The pull-out test is demonstrated in Figure $1 \mathrm{~b}$ and the sleeve configuration is shown in Figure 1c.

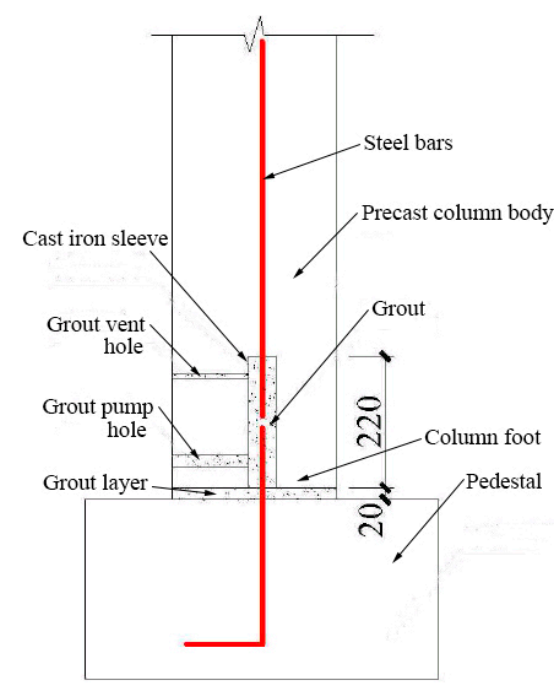

(a)

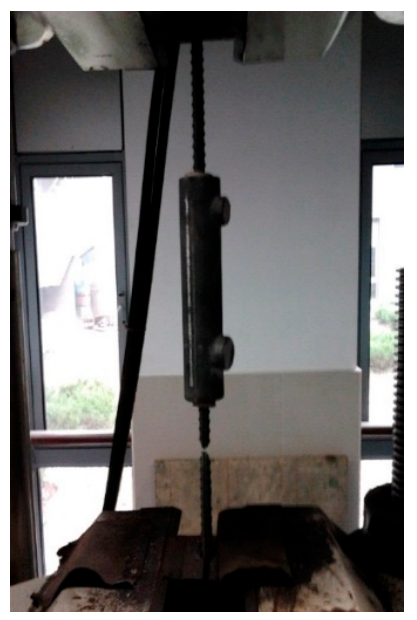

(b)

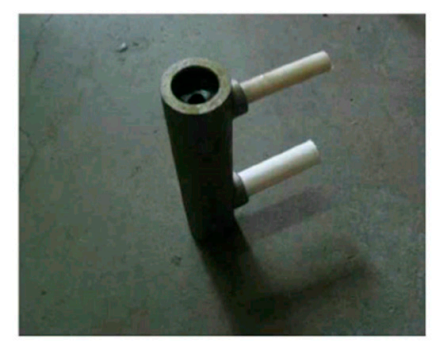

(c)

Figure 1. (a) Schematic diagram of the grouted splice sleeve (distances in $\mathrm{mm}$ ); (b) pull-out test of the grouted splice sleeve; (c) cast iron sleeve.

The objective of this paper is to study the seismic performance of precast concrete columns with grouted splice sleeves by experiments, and validate that this kind of joint connection of precast members have the same strength as cast-in-situ members. Four $300 \mathrm{~mm} \times 300 \mathrm{~mm}$ prefabricated columns with grouted splice sleeve connections and two $300 \mathrm{~mm} \times 300 \mathrm{~mm}$ cast-in-situ columns are made. Through low cyclic repeated loading and monotonic loading tests, the seismic performance of the columns is compared between the prefabricated ones and the cast-in-situ ones, including the load-displacement curve, crack load, yield load, ultimate load, ductility, stiffness, etc. Based on the comprehensive analysis of the experimental results, some recommendations on practical seismic design pertaining to the precast concrete members connected by the grouted splice sleeve are proposed. 


\section{Test Setup}

In this section, pseudo-static tests on four precast columns and two cast-in-situ columns have been conducted. Through these tests, the seismic performance of the cast-in-situ columns has been compared with that of the precast columns. There are six specimens: four of them are prefabricated columns whose numbers are 2\#, 3\#, 5\#, and 7\#, while other two specimens, $1 \#$ and 6\#, are cast-in-situ columns set as the control group. The size and reinforcement of these two types of columns are shown in Figure 2, where "4D16" means that the number of steel bars is four, and the diameter of the steel bars is $16 \mathrm{~mm}$. "D8@100" means that the diameter of the stirrups is $8 \mathrm{~mm}$, and the spacing of the stirrups is $100 \mathrm{~mm}$.

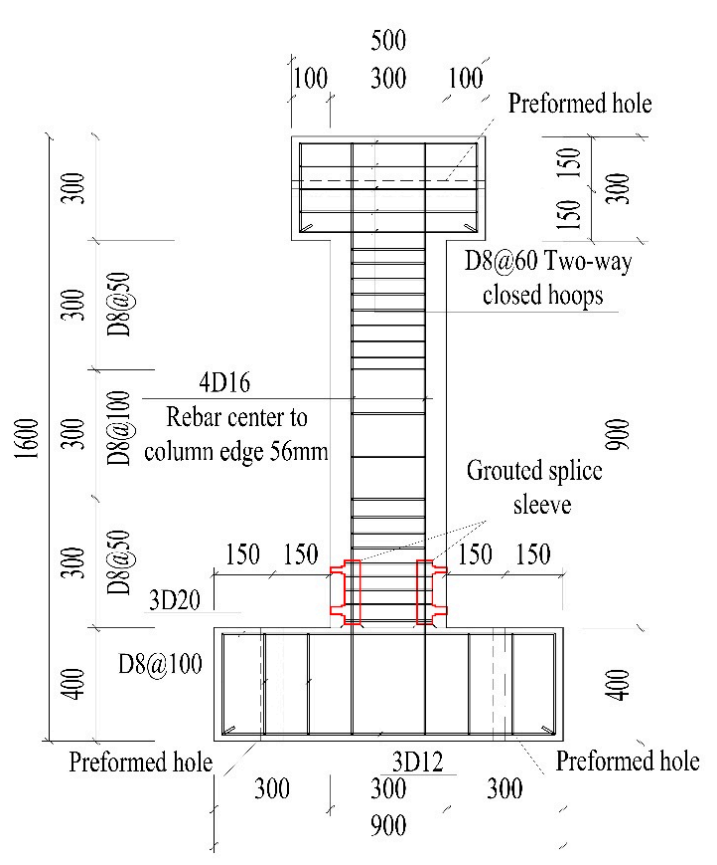

(a)

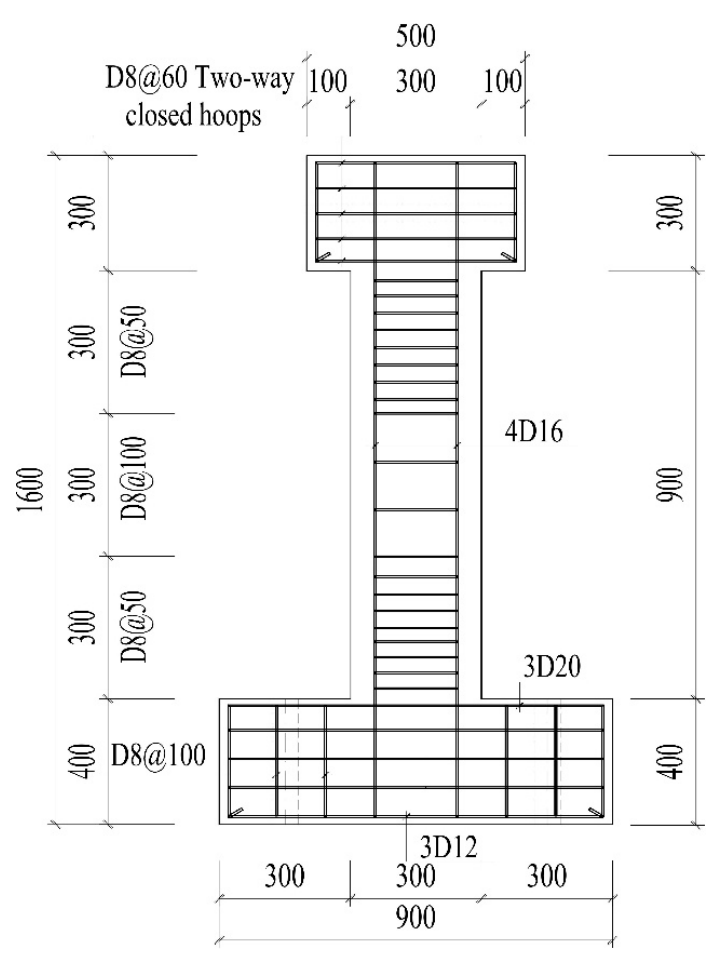

(b)

Figure 2. Elevation of columns (distances in $\mathrm{mm}$ ): (a) prefabricated column; (b) cast-in-situ column. Intensity grade of rebar used in the columns is HRB400 whose nominal yield strength is $400 \mathrm{MPa}$, and the diameter of the preformed hole is $45 \mathrm{~mm}$.

\subsection{Material Strength}

\subsubsection{Steel Bar Strength}

HRB400 steel bars are utilized to make the specimens. Table 1 lists the actual measured yield strength $f_{y}$ and ultimate strength $f_{u}$, which are obtained through material tests on three steel bars. In Table 1, the yield stain is expressed as $\varepsilon_{y}=f_{y} / E_{s}$ and the elastic modulus is $E_{s}=2.0 \times 10^{5} \mathrm{MPa}$.

Table 1. Actual tensile strength of the steel bars.

\begin{tabular}{cccc}
\hline$d(\mathbf{m m})$ & $\left.f_{\boldsymbol{y}} \mathbf{( M P a}\right)$ & $\left.f_{u} \mathbf{( M P a}\right)$ & $\varepsilon_{y}\left(\times \mathbf{1 0}^{-\mathbf{6}}\right)$ \\
\hline 8 & 427.4 & 626.7 & 2137 \\
12 & 455.4 & 608.4 & 2277 \\
16 & 458.3 & 625.8 & 2292 \\
20 & 439.9 & 649.0 & 2200 \\
\hline
\end{tabular}




\subsubsection{Concrete Compressive Strength}

Table 2 shows the actual measured cubic compressive strength of concrete, which is obtained from the 28 days compressive strength of three test cubes with a side length of $150 \mathrm{~mm}$. Additionally, the compressive strength of grout is determined by averaging the cubic compressive strength of three test cubes with a side length of $70 \mathrm{~mm}$.

Table 2. Actual cubic compressive strength $f_{c u}$ of the concrete and grout of the specimens.

\begin{tabular}{ccc}
\hline Specimen Number & Concrete (MPa) & Grout (MPa) \\
\hline 1\# (cast in situ) & 52.1 & 125.6 \\
2\# & 53.8 & 128.0 \\
3\# & 57.1 & 121.6 \\
$5 \#$ & 38.8 & 118.1 \\
6\# (cast in situ) & 52.7 & 125.3 \\
7\# & 51.1 & 127.7 \\
\hline
\end{tabular}

\subsection{Test Method}

Currently, there are three main kinds of indoor seismic test methods for structural models, namely the pseudo-static test, pseudo-dynamic test, and shaking table test. The pseudo-static test, also called the low cyclic repeated loading test, has been applied to study seismic performance of various kinds of building structures or members by many scholars [36-38]. The experimental results obtained from the low cyclic repeated loading test, such as hysteresis loops, load-displacement curves, stiffness degradation curves, viscous damping coefficient, and displacement ductility coefficient, can indicate the seismic performance of structural members effectively, including the energy-dissipating capacity, load-carrying capability, and ductility. Furthermore, compared with other test methods, the pseudo-static test is more economic, feasible, and has few requirements on the test facility, which makes it not only convenient for researchers to watch the process of cracking and the failure status of structures, but also realizable to check the test data and the working status of the test apparatus, as well as to modify the loading process according to actual needs. Based on the advantages of the pseudo-static test mentioned above, this paper uses it as the test method.

\subsection{Test Apparatus and Loading Laws}

\subsubsection{Test Apparatus}

There are many test loading methods to study the seismic performance of frame columns, among which the simply supported beam loading and the cantilever beam loading are the most common ways. In tests of high strength concrete square-section columns carried out at the University of Nebraska Lincoln, the simply supported beam loading was chosen [39], while in tests of high strength concrete columns conducted at Toronto University and Clarkson University, the cantilever beam loading was employed [40,41]. In this test, the cantilever beam loading was adopted and an actuator with a maximum loading of 10 tons was utilized to exert the cyclic load. The loading equipment is shown in Figure 3. 


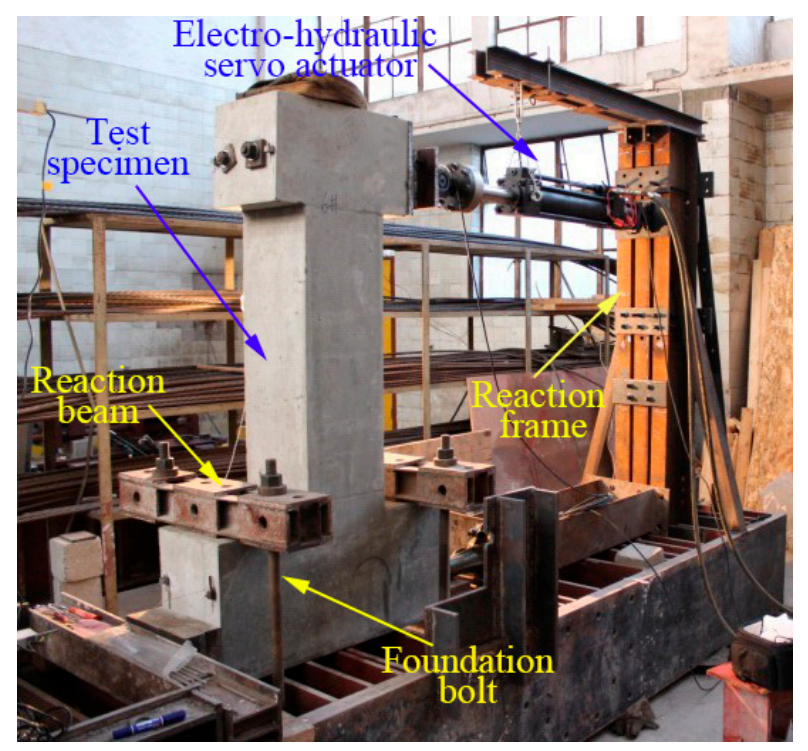

Figure 3. Test apparatus.

\subsubsection{Loading Laws}

Two load cases are considered in this test, namely low cyclic repeated loading and static loading. Specifically, the low cyclic repeated loading can be divided into two phases, where the maximum force of $0.5 N_{c u}$ and $0.75 N_{c u}\left(N_{c u}\right.$ is the estimated ultimate load) are repeatedly exerted, respectively. In the first loading phase, three cyclic loads are exerted previously with the maximum value of 0.4 times of the cracking load. Subsequently, the peak loading value is set as $0.5 N_{c u}$ exerted by a sine wave with a period of $60 \mathrm{~s}$ for each waveform, and the number of cyclic loadings is 30 times. During the second loading phase, the peak loading value is set as $0.75 \mathrm{~N}_{c u}$ and specimens are loaded 100 times repeatedly by sine waves with a period of $45 \mathrm{~s}$ for each waveform.

When the low cyclic repeated loading process is finished, static loads are similarly applied to the same location of specimens that low cyclic repeated loads are taken from. Specimens are loaded continuously from zero to failure and the static loading is ended when the load-carrying capability of the specimens falls to $85 \%$ of their ultimate load-carrying capability.

\subsubsection{Measurement Design}

\section{Layout of the Displacement Sensor}

In order to measure rotation capacity of the column foot, two displacement sensors are arranged at the pedestal and the location $200 \mathrm{~mm}$ above the pedestal, respectively. Additionally, another displacement sensor is deployed at the load-end location of the column to measure the displacement change of this section. The layout of the displacement sensors is shown in Figure 4a.

\section{Layout of the Strain Gauge}

Since there is the maximum moment at the lower end of the column, four strain gauges are set at the four longitudinal steel bars at the corner. As for the precast column, an additional four strain gauges are installed at the rebar near the top of the sleeve. The detailed arrangement plan is shown in Figure $4 b, c$.

The main measure contents in this test are the horizontal loads, horizontal displacement, longitudinal strain of the steel bars, and crack width of concrete. All measured data are collected by a data collector; meanwhile, the horizontal loads and horizontal displacement are transferred to the $X Y$-function recorder, which is employed to plot $P-\Delta$ hysteretic curves. 


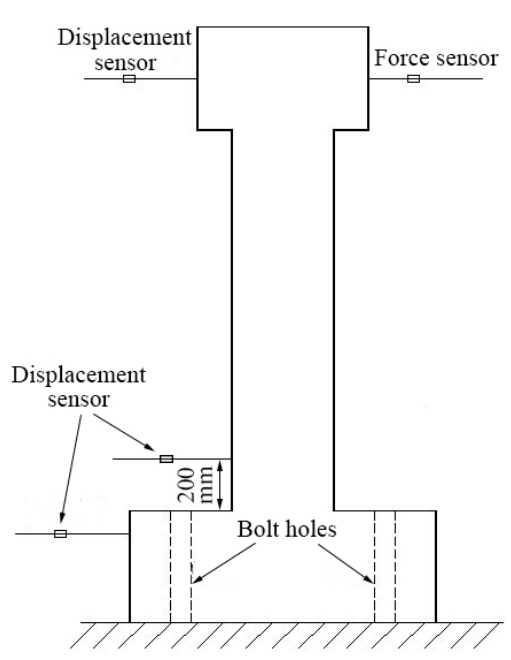

(a)

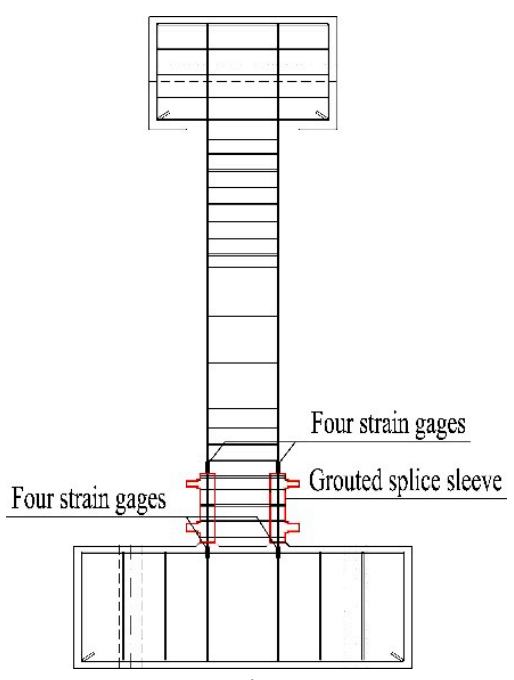

(b)

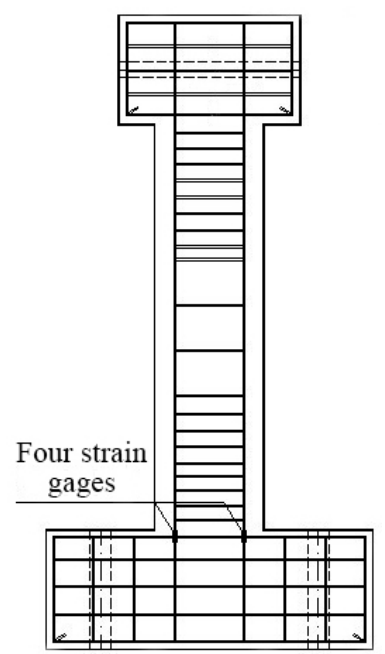

(c)

Figure 4. Measuring point layout: (a) displacement sensors; (b) strain gauges in the precast column; (c) strain gauges in the cast-in-situ column.

\section{Test Results and Discussion}

\subsection{Test Phenomenon}

According to the test phenomena, it is indicated that under low cyclic repeated horizontal load, the overall loading process of the columns can be divided into two stages, namely the uncracking stage and cracking stage. During the uncracking stage, there were no cracks in the specimens and the stress of the longitudinal steel bars was extremely small, which means that members are at the elastic stage, and the internal force is mainly resisted by the concrete. At the cracking stage, the stress of the longitudinal steel bars where cracks happened increased rapidly and many cracks appeared soon after. Finally, steel bars at the bottom of the columns began to yield.

Under static load, the loading history of the columns is also divided into two stages, namely the yield stage and failure stage. At the yield stage, the longitudinal steel bars of columns yielded successively until the load-carrying capability of columns reached their peak. The failure stage ended up with the phenomenon that columns were destroyed seriously or their load-carrying capability dropped to $85 \%$ of the ultimate value. Considering the similarity of the test phenomena among these specimens, only the phenomena of specimen $1 \#, 3 \#, 5 \#$, and $6 \#$ will be illustrated at length in the following section. The loading conditions of column $1 \#, 3 \#, 5 \#$, and $6 \#$ are listed in Table 3.

Table 3. Loading conditions of columns 1\#, 3\#, 5\#, and 6\#.

\begin{tabular}{cccccc}
\hline \multirow{2}{*}{$\begin{array}{c}\text { Specimen } \\
\text { Number }\end{array}$} & \multicolumn{2}{c}{ Low Cyclic Repeated Loading } & \multicolumn{2}{c}{ Static Loading } \\
\cline { 2 - 5 } & $\begin{array}{c}\text { Preloading } \\
\text { Value }\end{array}$ & $\begin{array}{c}\text { Peak Value at } \\
\text { First Stage }\end{array}$ & $\begin{array}{c}\text { Peak Value at } \\
\text { Second Stage }\end{array}$ & Yield Value & Failure Value \\
\hline $1 \#$ (cast in situ) & $\pm 7 \mathrm{kN}$ & $\pm 13 \mathrm{kN}$ & $\pm 19.5 \mathrm{kN}$ & $47.45 \mathrm{kN}$ & $54.19 \mathrm{kN}$ \\
$3 \#$ & $\pm 4 \mathrm{kN}$ & $\pm 10 \mathrm{kN}$ & $\pm 19.5 \mathrm{kN}$ & $47.77 \mathrm{kN}$ & $65.55 \mathrm{kN}$ \\
$5 \#$ & $\pm 4 \mathrm{kN}$ & $\pm 10 \mathrm{kN}$ & $\pm 19.5 \mathrm{kN}$ & $37.54 \mathrm{kN}$ & $40.53 \mathrm{kN}$ \\
$6 \#$ (cast in situ) & $\pm 4 \mathrm{kN}$ & $\pm 10 \mathrm{kN}$ & $\pm 19.5 \mathrm{kN}$ & $47.87 \mathrm{kN}$ & $56.29 \mathrm{kN}$ \\
\hline
\end{tabular}

\subsubsection{Phenomena of Column 1\#}

For column 1\#, a cast-in-situ specimen, the interconnected cracks at both sides appeared at the 10th load cycle during the first stage of low cyclic repeated loading. In the second loading stage, a crack appeared with the width of $0.3 \mathrm{~mm}$ after the specimen was subjected to the 53rd cyclic load. In the 
failure stage, the tensile cracks developed obviously while the concrete in the compressive zone was crushed. The detailed crack distribution and failure mode of column 1\# are shown in Figure 5.
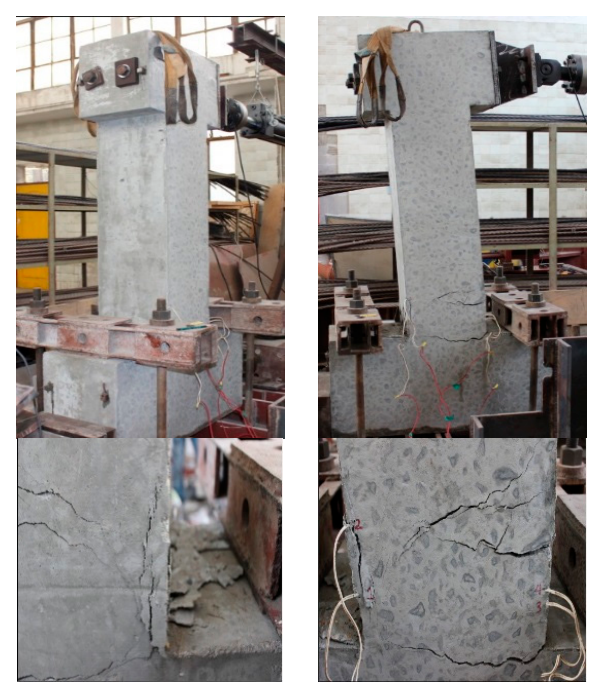

Figure 5. Cracks and failure mode of column 1\#.

\subsubsection{Phenomena of Column 3\#}

Since the clearance between the column body and pedestal was not sealed rigidly during installation, the grout flowed when grouting, leading to severe out-of-plane inclination of column $3 \#$. In the first low cyclic repeated loading stage, when the specimen was loaded at the 10th cycle, the micro-cracks at the connection part of the column foot appeared. During the second stage, the surface $300 \mathrm{~mm}$ above the column foot cracked. In the static loading stage, cracks penetrated at the tensile side of the column and then they extended to the opposite face of the column. When the static load reached $52 \mathrm{kN}$, new cracks appeared at the upper location of the original ones. In the failure stage, the cracks at the tensile side of the specimen developed severely while the compressive zone of the concrete column was crushed. The detailed crack distribution and failure mode of column $3 \#$ are shown in Figure 6.
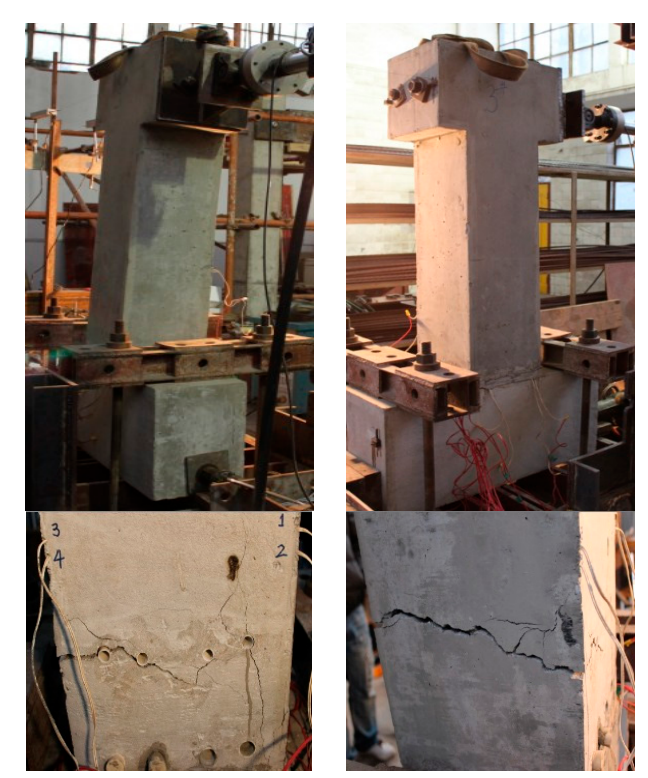

Figure 6. Cracks and failure mode of column 3\#. 


\subsubsection{Phenomena of Column 5\#}

Actually, column 5\# is the most ideal specimen that does not have any inclination. In the first low cyclic repeated loading stage, the connection between the upper and lower portions sealed by grout had cracks appear at the back side of the column during the 11th load cycle. When the column was subjected to the 28th load cycle, the connection at the front side of the column cracked. New cracks did not appear until the second stage ended. In the static load stage, the width of the crack $250 \mathrm{~mm}$ above the column foot was over $2.0 \mathrm{~mm}$. In the failure stage, the tensile cracks were obvious while the concrete in the compressive zone was crushed. The detailed crack distribution and failure mode of column 5\# are shown in Figure 7.

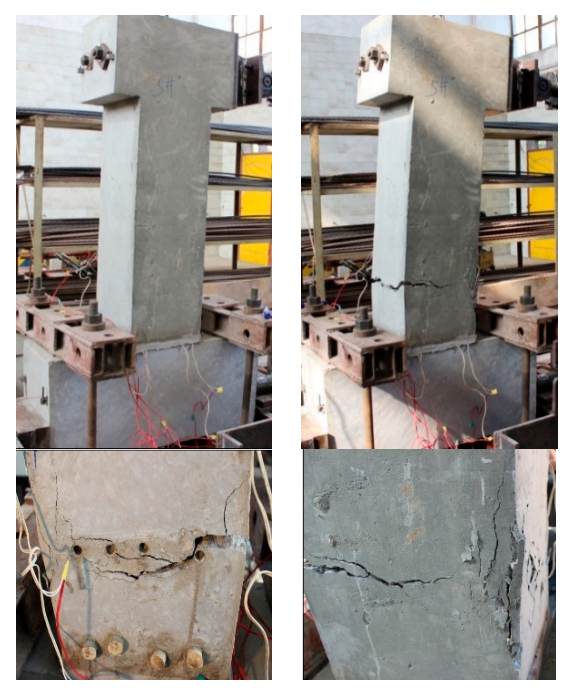

Figure 7. Cracks and failure mode of column 5\#.

\subsubsection{Phenomena of Column 6\#}

Column 6\# is a cast-in-situ specimen with no strain gauges. In the low cyclic repeated loading stage, after 20 cyclic loads were applied, the specimen began to crack slightly. In the second stage, a crack appeared when the specimen suffered the 3rd cycle load, and at the 10th load cycle, this crack was interconnected at both sides of the column. In the static load stage, the second obvious crack appeared at $200 \mathrm{~mm}$ above the lower end of the column when the stress of the specimen increased to its yield value. When the load was up to $51.40 \mathrm{kN}$, the third obvious crack appeared. Finally, the concrete at the compressive zone was crushed to failure while the cracks at the tensile zone developed obviously. The detailed crack distribution and failure mode of column 6\# are shown in Figure 8.
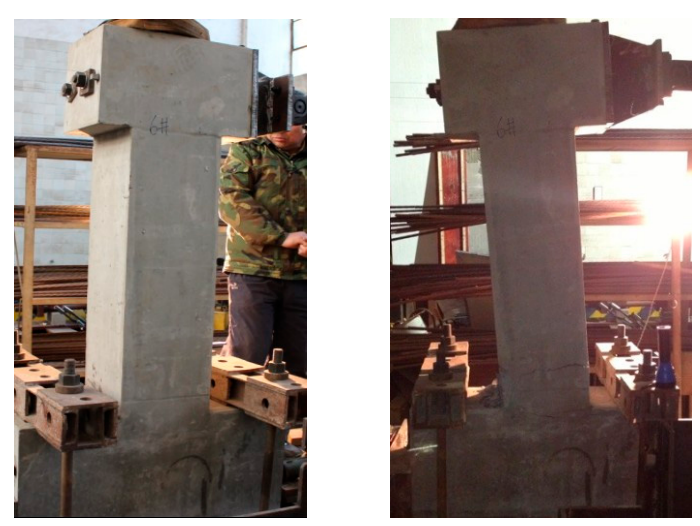

Figure 8. Cont. 

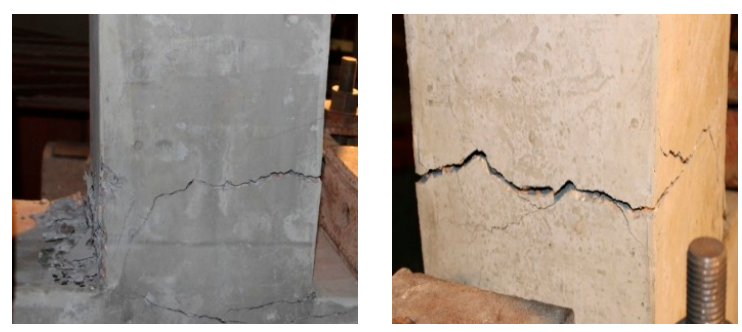

Figure 8. Crack and failure mode of column 6\#.

According to the test phenomena presented above, the prefabricated columns have fundamentally the same failure mode as that of the cast-in-situ columns, indicating that both of them completely lose the ultimate load-carrying capability due to bending failure. Under this mode of failure, the cracks widened visibly at the tensile edge of the concrete, and the columns failed by crushing of the concrete in the compressive zone and by tensile yielding of the vertical reinforcement bars in the tensile zone.

However, differences exist in the crack distribution between these two types of columns. For the cast-in-situ columns, the first crack appeared at the bottom of the column, and then it moved toward the opposite side, and finally the interconnected crack almost overlapped with the interface between the column body and the pedestal, as shown in Figure 9a. However, for the prefabricated columns, the width of the horizontal cracks at the column foot were not large, whereas the horizontal cracks above the sleeve were wide, and they propagated downward and became diagonal cracks with a large width, as shown in Figure 9b. The differences in the crack distribution between these two types of columns may be attributed to the following reasons. First, at the connection part of the prefabricated columns, the stress existing in the steel bars is transferred to the sleeve via mortar, and thus the sleeve whose tensile strength is higher than that of the steel bars replaces the steel bars to bear the loads. Furthermore, the compressive strength of grout filled in the sleeve is higher than that of concrete. Consequently, the strength of precast columns at the connection part is enhanced, making the plastic hinge move upward, as illustrated in Figure 9c; Second, for the prefabricated columns, the compressive strength of the two-centimeter-thick mortar layer is low, and thus the bonding strength between the column foot and pedestal is weak, which can possibly lead to the column body separating from the pedestal before failure, as illustrated in Figure 9d.

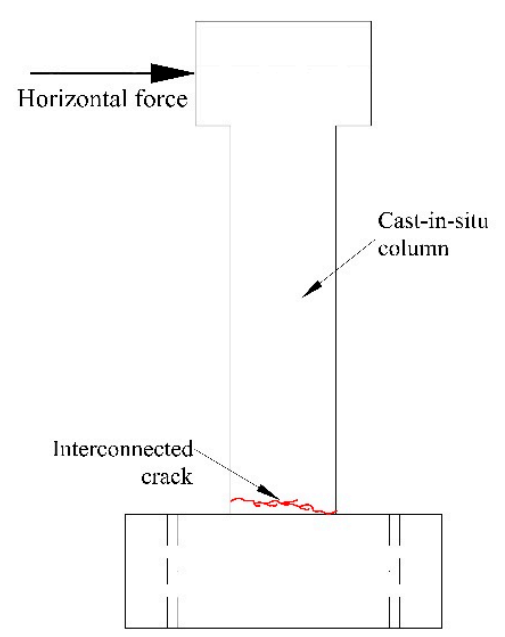

(a)

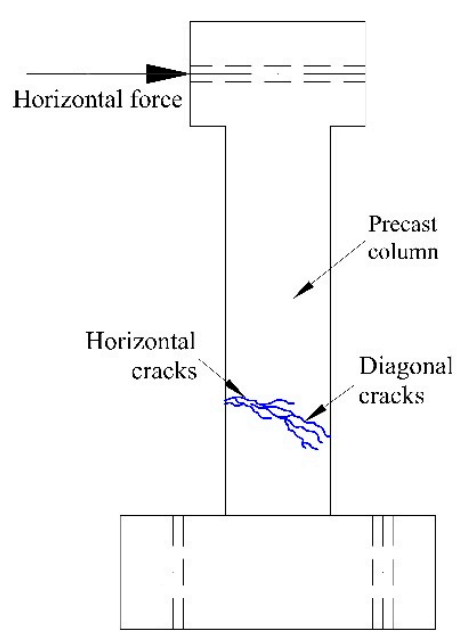

(b)

Figure 9. Cont. 


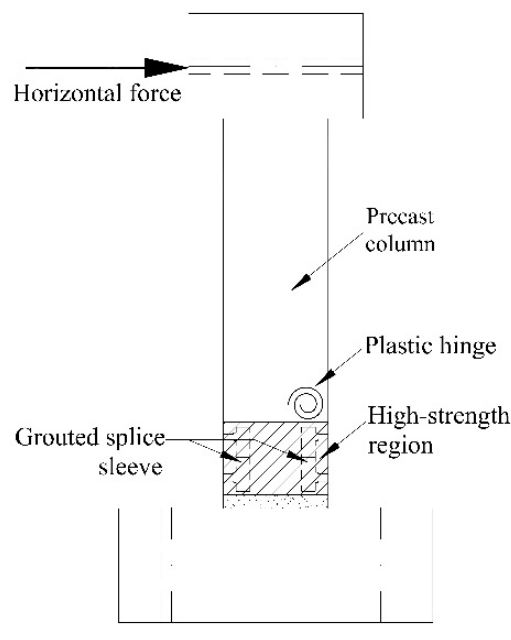

(c)

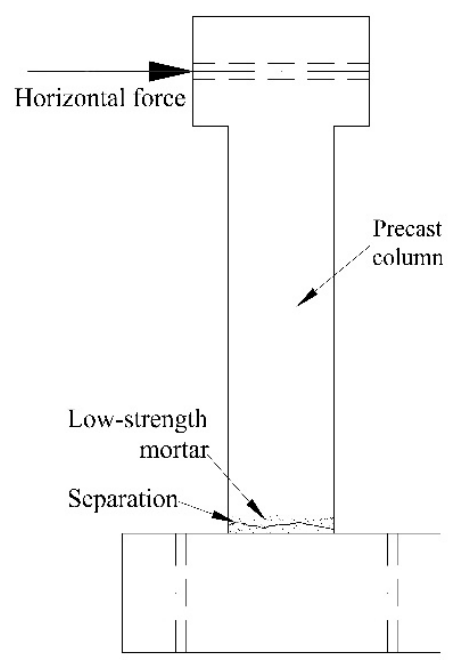

(d)

Figure 9. (a) Crack distribution of the cast-in-situ columns; (b) crack distribution of the precast columns; (c) schematic of the first reason; (d) schematic of the second reason.

It should be noted that although inclination appeared in some columns resulting from the low compressive strength of the two-centimeter-thick mortar layer between the column foot and pedestal, this problem can be avoided in practical engineering if high-strength mortar is utilized.

\subsection{Discussion on Test Results}

\subsubsection{Hysteresis Loops}

The hysteresis curve shows the deformation performance of structures (or members), which provides an important reference for analyzing their seismic performance. The geometrical shape of the hysteresis loop represents the capacity of structures to be restored to their original status when loads are removed. Based on the shape of the hysteresis curve, not only the seismic performance of structures can be qualitatively determined but also the load-carrying capability, stiffness, failure status, deformation, ductility, energy-dissipating ability, and nonlinear properties of structures are able to be obtained. In this section, the typical specimens $1 \#$ and 5\# are selected and their hysteresis loops are shown in Figures 10 and 11.

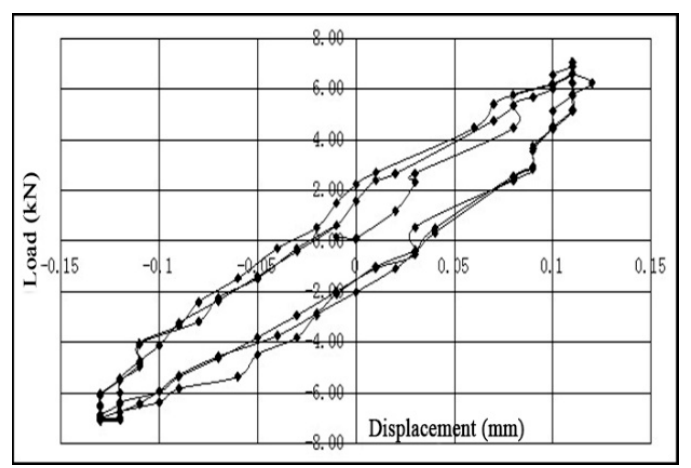

(a)

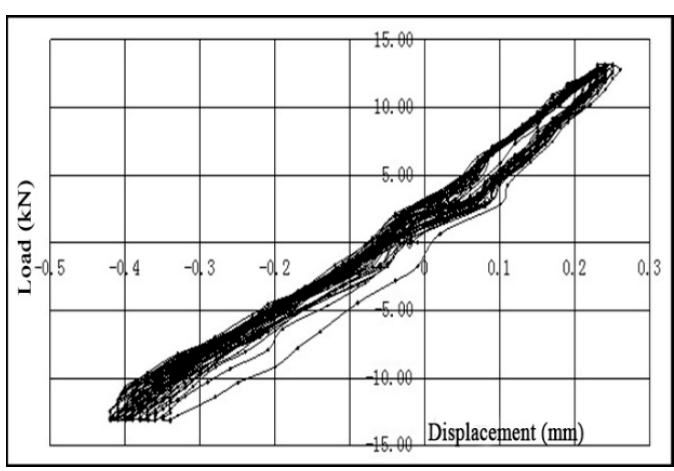

(b)

Figure 10. Cont. 


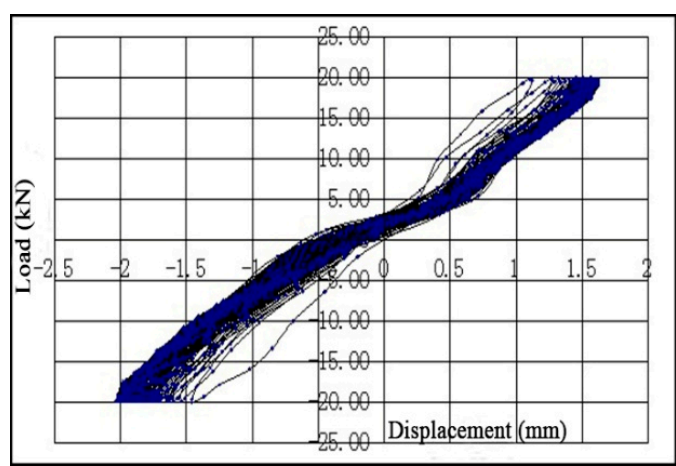

(c)

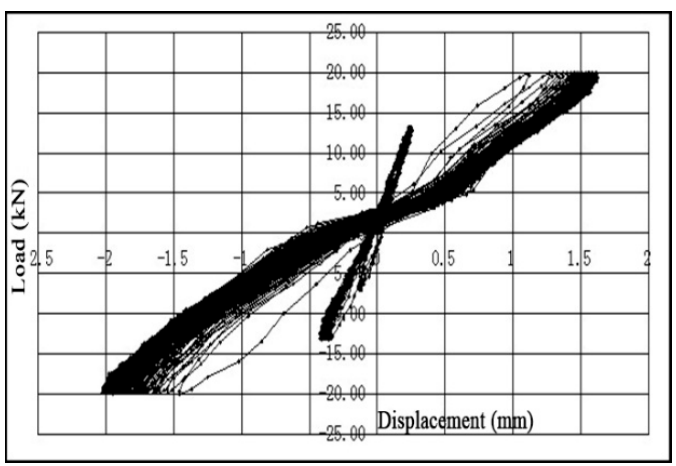

(d)

Figure 10. Hysteresis loops of column 1\#: (a) hysteresis loops at the preloading stage; (b) hysteresis loops at the first stage; (c) hysteresis loops at the second stage; (d) hysteresis loops of the overall cyclic loading process.

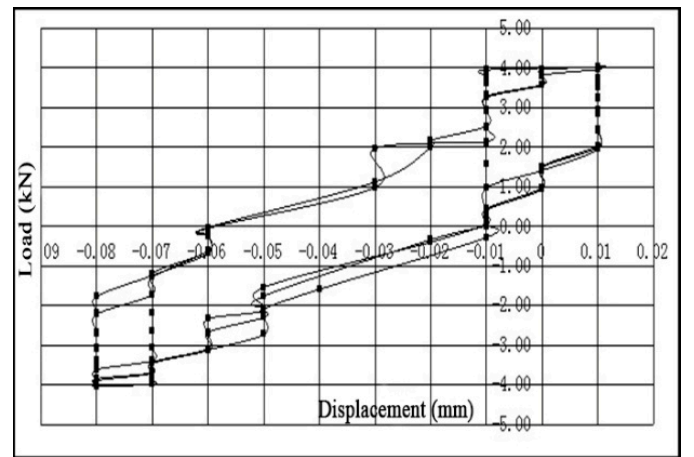

(a)

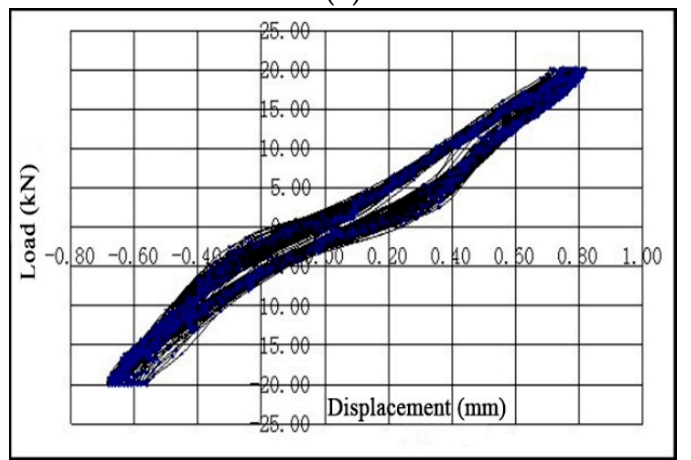

(c)

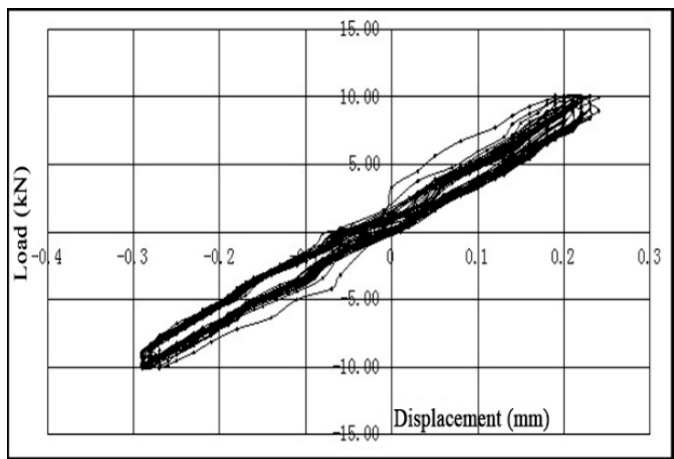

(b)

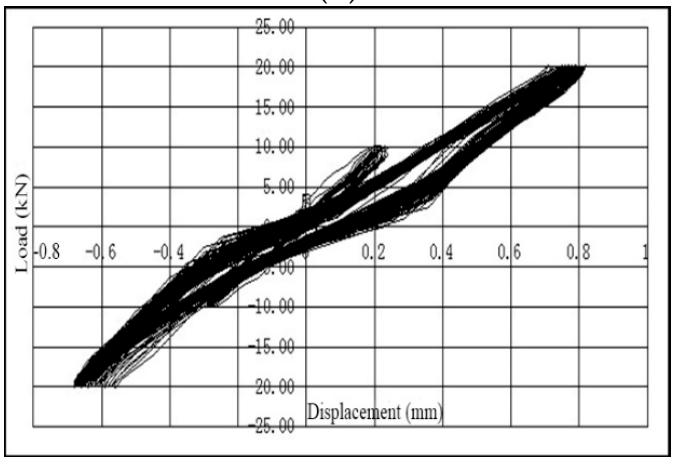

(d)

Figure 11. Hysteresis loops of column 5\#: (a) hysteresis loops at the preloading stage; (b) hysteresis loops at the first stage; (c) hysteresis loops at the second stage; (d) hysteresis loops of the overall cyclic loading process.

Several common features of the specimens are summarized as follows:

(1) In the preload stage of low cyclic repeated loading, the hysteresis loops are relatively full and show shuttle shapes, whereas in the first stage, the hysteresis loops begin to show the rheostriction effect due to the generation and development of cracks in the concrete. In the second stage, the rheostriction effect of the curve becomes obvious and the hysteresis loops present arch and reversed S shapes.

(2) Under the load with the same level, the area that the hysteresis loops envelop is smaller and smaller, indicating that the energy-dissipating capacity is degrading. Moreover, the residual 
deformation and the area enveloped by the hysteresis loops is increasing with load boosting; meanwhile the curve is inclined to the displacement axis.

(3) For the loading curve, under the load with the same level, the displacement increases with the increasing number of loops, while the slope of the curve diminishes, indicating the stiffness degradation of the specimens when they suffer repeated loads. The curve slope reduces significantly when the loading enters into the second stage. Regarding the unloading curve, it has the same change law in terms of the curve slope with the increasing number of loops. When all the loads are removed, there is a residual deformation in the specimens and it can be intensified with the repeated loading and unloading process.

\subsubsection{Load-Displacement Curves in the Failure Stage}

The typical load-displacement curves of column $1 \#$ and $5 \#$ in the failure and the whole loading process are drawn as shown in Figure 12.

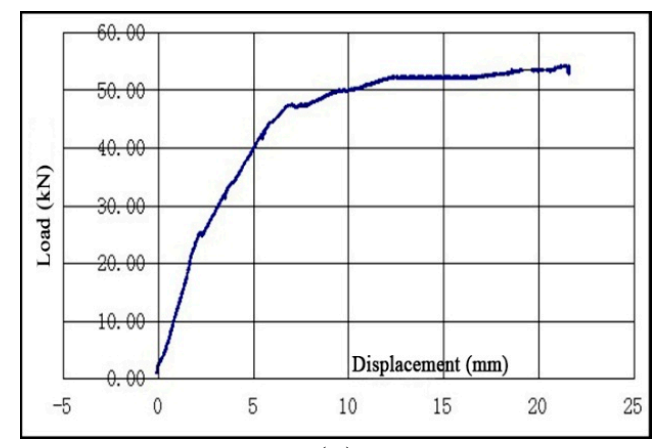

(a)

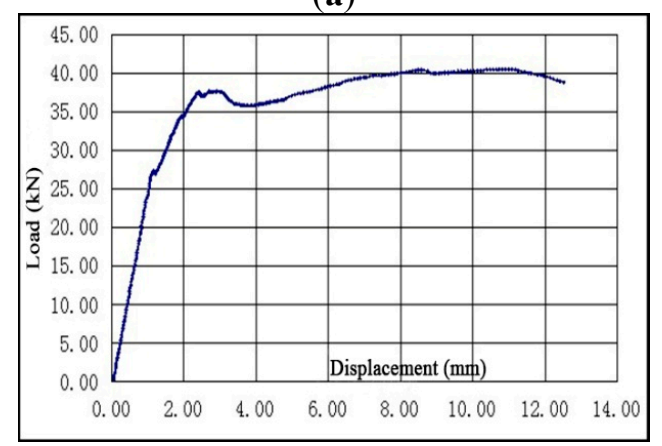

(c)

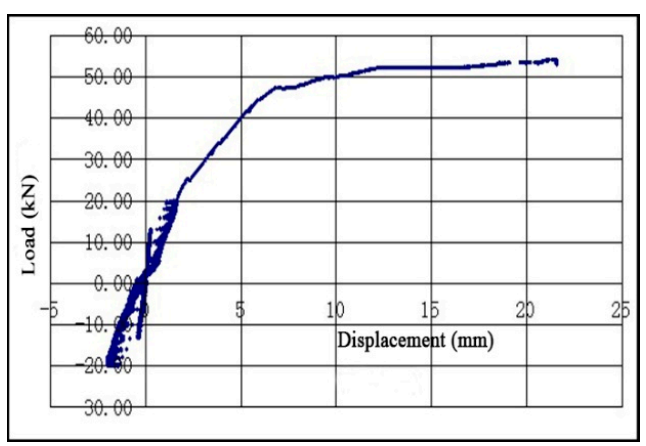

(b)

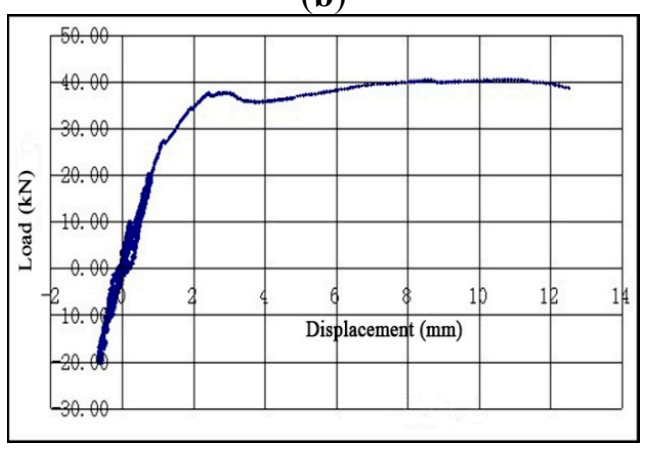

(d)

Figure 12. Load-displacement curves: (a) column 1\# in the failure stage; (b) column 1\# in the whole loading process; (c) column $5 \#$ in the failure stage; (d) column $5 \#$ in the whole loading process.

The load-carrying capability of each specimen is displayed in Table 4. Columns 1\# and 6\# are cast-in-situ specimens and their strengths are basically consistent. The load-carrying capability of the prefabricated columns 2\#, 3\#, and 7\# varies due to insufficient grouting in their sleeve connection, which can be attributed to the strength of the cement mortar that is utilized to seal the edge being inadequate. Furthermore, the grout with a higher strength than concrete leaks out and diffuses at the column foot, leading to these specimens possessing different load-carrying capabilities. Column $2 \#$ generates in-plane inclination and the loading direction at its failure stage is opposite to that of the inclination, resulting in a higher load-carrying capability. On the contrary, column $7 \#$ also generates in-plane inclination but its inclination has the same direction with that of the loading at the failure phase, leading to low load-carrying capability. For column 3\#, it inclines out of plane but has the largest load-carrying capability among these specimens. The possible relevant causes for that may be: (1) the severe out-of-plane inclination may give rise to the smaller axial force exerted on the column; 
(2) a great deal of grout leaks out, and finally the high-strength mortar replaces concrete to bear the compression. As for column 5\#, it is grouted sufficiently because of no grout running out, and finally, its yield capacity is $80 \%$ that of the cast-in-situ columns and its ultimate load-carrying capability is $70 \%$ that of the cast-in-situ columns.

Table 4. Load-carrying capability of the specimens.

\begin{tabular}{cccc}
\hline Specimen & Cracking Load $\mathbf{( k N )}$ & Yield Load $\mathbf{( k N )}$ & Ultimate Load $\mathbf{( k N )}$ \\
\hline 1\# (cast in situ) & 25.43 & 47.45 & 54.19 \\
2\# & 27.57 & 48.60 & 59.81 \\
3\# & 28.54 & 47.77 & 65.55 \\
5\# & 27.38 & 37.54 & 40.53 \\
6\# (cast in situ) & 26.17 & 47.87 & 56.29 \\
7\# & 27.04 & 28.93 & 39.76 \\
\hline
\end{tabular}

\subsubsection{Stiffness Degradation Curves}

The stiffness of the column will degrade after cracking. Under low cyclic repeated horizontal loading, the computational formula of its stiffness can be expressed as

$$
K_{i}=\frac{\left|+P_{i}\right|+\left|-P_{i}\right|}{\left|+\Delta_{i}\right|+\left|-\Delta_{i}\right|}
$$

where $K_{i}$ means the secant stiffness of the specimen under the $i$ th level load; $+P_{i},-P_{i}$ are the peak load values of the first circulation under the $i$ th level load and $+\Delta_{\mathrm{i}},-\Delta_{\mathrm{i}}$ are their corresponding displacements. Due to the small number of load levels in the low cyclic repeated loading stage, the stiffness degradation in the failure stage is considered simultaneously, and the stiffness value is obtained from Equation (2) whose calculated results can qualitatively reflect the change tendency of stiffness degradation during the whole loading process.

$$
K=\frac{P}{\Delta}
$$

Calculate the stiffness value of specimens at each loading stage, including initial stiffness $K_{30}$, cracking stiffness $K_{c r}$, yield stiffness $K_{y}$, and ultimate stiffness $K_{u}$. Since the reading of the displacement sensor has a large relative error at the beginning of the test, the secant stiffness at the end of the first stage of the low cyclic repeated loading is regarded as the initial stiffness $K_{30}$, and the secant stiffness at the end of the second stage of the low cyclic repeated loading is denoted as $K_{130}$. Then calculate the relative stiffness of $K_{130}, K_{c r}, K_{y}$, and $K_{u}$ with respect to $K_{30}$. The stiffness of each specimen at each loading stage is shown in Table 5. It can be concluded from Table 5 that the cast-in-situ columns have a faster velocity of stiffness degradation. Column $5 \#$ has the most successful grouting and its stiffness degradation process after yielding is similar with that of the cast-in-situ columns.

Table 5. Stiffness value of the specimens at each load stage $(\mathrm{kN} / \mathrm{mm})$.

\begin{tabular}{cccccccccc}
\hline Specimen & $\boldsymbol{K}_{\mathbf{3 0}}$ & $\boldsymbol{K}_{\mathbf{1 3 0}}$ & $\boldsymbol{K}_{\mathbf{1 3 0}} / \boldsymbol{K}_{\mathbf{3 0}}$ & $\boldsymbol{K}_{\boldsymbol{c r}}$ & $\boldsymbol{K}_{\boldsymbol{c r}} / \boldsymbol{K}_{\mathbf{3 0}}$ & $\boldsymbol{K}_{\boldsymbol{y}}$ & $\boldsymbol{K}_{\boldsymbol{y}} / \boldsymbol{K}_{\mathbf{3 0}}$ & $\boldsymbol{K}_{\boldsymbol{u}}$ & $\boldsymbol{K}_{\boldsymbol{u}} / \boldsymbol{K}_{\mathbf{3 0}}$ \\
\hline 1\# (cast in situ) & 40.37 & 14.21 & $35.20 \%$ & 11.26 & $27.89 \%$ & 6.17 & $15.28 \%$ & 2.52 & $6.24 \%$ \\
2\# & 47.9 & 33.57 & $70.08 \%$ & 22.58 & $47.14 \%$ & 18.71 & $37.93 \%$ & 6.68 & $13.95 \%$ \\
3\# & 43.96 & 28.14 & $64.01 \%$ & 21.03 & $47.84 \%$ & 16.64 & $37.85 \%$ & 3.98 & $8.00 \%$ \\
5\# & 38.81 & 26.81 & $69.07 \%$ & 23.59 & $60.78 \%$ & 6.90 & $17.78 \%$ & 3.78 & $9.74 \%$ \\
6\# (cast in situ) & 87.48 & 27.39 & $31.31 \%$ & 20.32 & $23.23 \%$ & 12.87 & $14.72 \%$ & 4.87 & $5.57 \%$ \\
7\# & 48.02 & 23.34 & $48.59 \%$ & 21.77 & $45.33 \%$ & 14.99 & $31.22 \%$ & 4.14 & $8.62 \%$ \\
\hline
\end{tabular}

For the sake of comparing and analyzing, the stiffness degradation curves of each specimen are drawn in the same coordinate system shown in Figure 13. It is shown that the stiffness of the 
specimens is relatively large at the first stage of low cyclic repeated loading, while it diminishes as the number of loops increases. At the second stage, since cracks appear and propagate, steel bars would slip longitudinally with respect to the adjacent concrete. Meanwhile, the velocity of stiffness degradation accelerates caused by the plastic deformation that occurred in the concrete. After the specimens achieve yield stress, the stiffness is reduced further but its velocity begins to slow down, and finally the stiffness degradation tends to be steady.

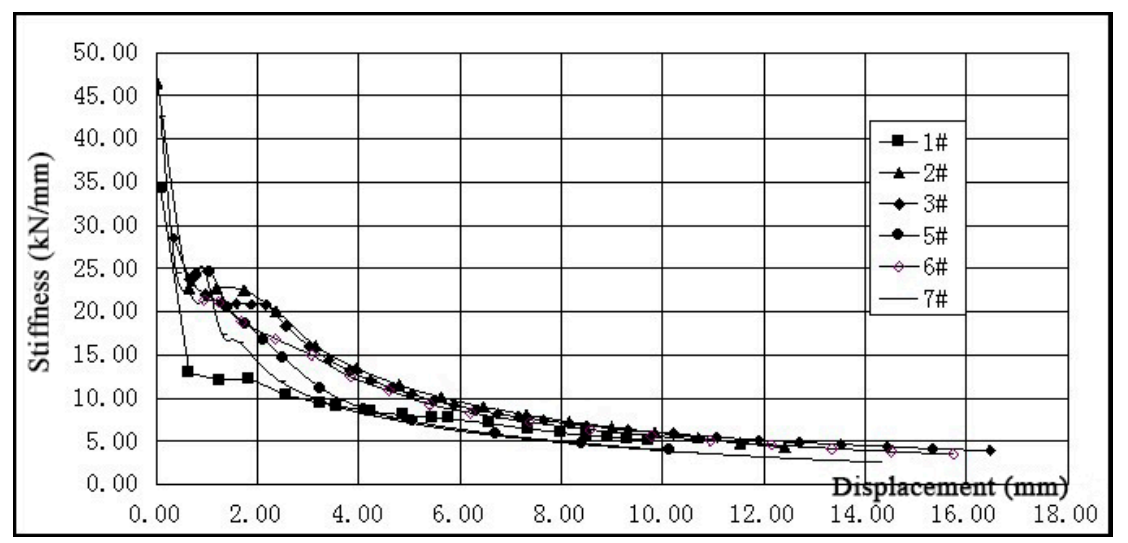

Figure 13. Stiffness degradation curves of the specimens.

\subsubsection{Energy Dissipation Capacity}

When the structure gets into the elastic-plastic state, its seismic performance mainly depends on the energy dissipation capacity. Figure 14 shows one loop of the hysteretic curve, by which the structural nonlinear energy absorption and dissipation capacity can be directly reflected from the shaded area ABCDA. Hence, the area that the $P-\triangle$ hysteresis curve envelops represents the structural ductility and energy-dissipating ability. The larger area that the hysteretic curve envelops, the more energy that structure dissipates, which is conducive to structural earthquake-resistant behavior.

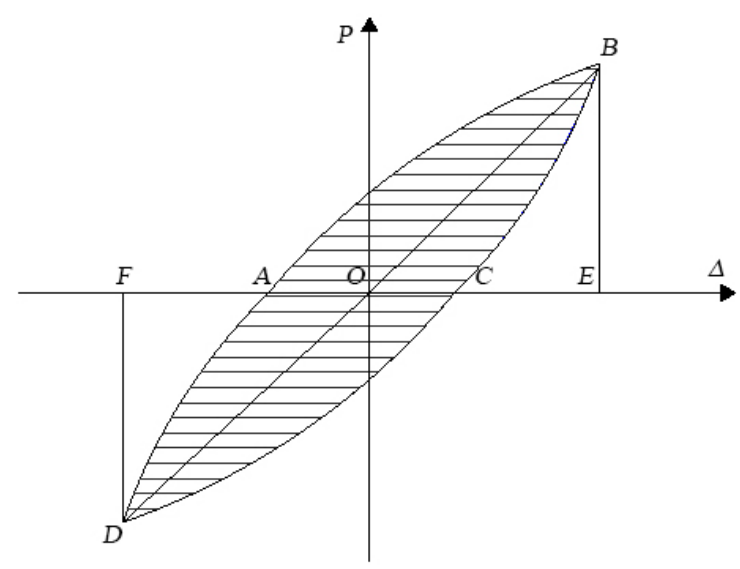

Figure 14. Schematic diagram of computing the viscous damping coefficient.

The viscous damping coefficient $h_{e}$ is one of the main indexes that reflects the structural ability to dissipate energy. Specifically, it can be calculated by Equation (3) [42]:

$$
h_{e}=\frac{1}{2 \pi} \cdot \frac{A_{\text {rea }}(A B C+C D A)}{A_{\text {rea }}(O B E+O D F)}
$$


The viscous damping coefficients $h_{e}$ of six specimens in terms of certain loading cycles are shown in Table 6, by which the following conclusions can be drawn:

(1) Since force-controlling loading is adopted, at the same level of the load, the stiffness reduces as the circle times increases, leading to a smaller viscous damping coefficient and a worse capacity of energy dissipation.

(2) The energy dissipation capacity of the specimens changes significantly in the first stage of low cyclic repeated loading and the specimens tend to lose the ability to dissipate energy in the whole second stage.

(3) The specimen 5\# grouted successfully with little grout leaking out has the largest viscous damping coefficients. Generally speaking, the prefabricated specimens have larger viscous damping coefficients than that of the cast-in-situ specimens, which demonstrates that the prefabricated columns have better performance on dissipating energy.

Table 6. Viscous damping coefficient $h_{e}$ of the specimens.

\begin{tabular}{ccccc}
\hline $\begin{array}{c}\text { Cycle Index } \\
\text { Specimen }\end{array}$ & $\mathbf{1}$ & $\mathbf{3}$ & $\mathbf{3 4}$ & $\mathbf{1 3 3}$ \\
\hline 1\# (cast in situ) & 0.153 & 0.123 & 0.049 & 0.011 \\
2\# & 0.183 & 0.164 & 0.073 & 0.059 \\
3\# & 0.145 & 0.128 & 0.039 & 0.024 \\
$5 \#$ & 0.249 & 0.171 & 0.067 & 0.047 \\
6\# (cast in situ) & 0.188 & 0.168 & 0.016 & 0.045 \\
$7 \#$ & 0.191 & 0.230 & 0.027 & 0.047 \\
\hline
\end{tabular}

\subsubsection{Ductility}

Ductility refers to the ability of a section to deform beyond its yield point without a significant strength loss, which is one of the essential indexes that reflect the inelastic deformation capacity of structures, members, and materials, and that evaluates the structural seismic performance. If a structure or a member has a strong inelastic deformation ability after yielding, it has a good ductility and ductile failure mode, but if not, brittle failure may happen more easily.

According to the deformation types that ductility represents, ductility is mainly categorized into the following four classifications: strain ductility, curvature ductility, rotation ductility, and displacement ductility. For displacement ductility, it is defined as the ratio of the ultimate displacement to the yield displacement. This paper utilizes the displacement ductility of the column end for analysis, denoted as $\mu_{\Delta}$, which is expressed as follows:

$$
\mu_{\Delta}=\frac{\Delta_{u}}{\Delta_{y}}
$$

where $\Delta_{u}$ denotes the effective horizontal displacement of the column when the horizontal loads imposed on the specimens begin to decline while the horizontal displacement continuously increases; $\Delta_{y}$ denotes the effective horizontal displacement of the column when the specimens yield. The effective horizontal displacement is obtained from the displacement at the top of column minus the displacement of the pedestal.

Based on Table 7, it is shown that all of the four prefabricated columns have a displacement ductility coefficient of the column end larger than 3.2, which satisfies the general regulation that the displacement ductility coefficient of the frame column should be larger than 2.0 [43], indicating that the prefabricated columns possess good ductility. 
Table 7. Displacement ductility coefficient of each specimen.

\begin{tabular}{cccc}
\hline Specimen & $\begin{array}{c}\text { Yield Displacement } \\
\boldsymbol{\Delta}_{\boldsymbol{y}} \mathbf{( \mathbf { m m } )}\end{array}$ & $\begin{array}{c}\text { Ultimate Displacement } \\
\boldsymbol{\Delta}_{\boldsymbol{u}}(\mathbf{m m})\end{array}$ & $\begin{array}{c}\text { Displacement Ductility } \\
\text { Coefficient } \boldsymbol{\mu}_{\boldsymbol{\Delta}}\end{array}$ \\
\hline 1\# (cast in situ) & 6.97 & 21.48 & 3.08 \\
2\# & 2.59 & 8.95 & 3.46 \\
3\# & 2.87 & 16.53 & 5.76 \\
$5 \#$ & 2.67 & 8.65 & 3.24 \\
6\# (cast in situ) & 3.35 & 11.79 & 3.52 \\
7\# & 2.09 & 10.26 & 4.91 \\
\hline
\end{tabular}

In conclusion, the prefabricated columns not only have high load-carrying capability but also have good ductility and energy-dissipating capacity, which meets the earthquake-resistant requirements. Through the experimental study, some important conclusions can be drawn as follows:

(1) According to the hysteresis loops of the specimens, the hysteresis curves of both the cast-in-situ columns and prefabricated columns have changed from plump shuttle shapes to reversed $S$ shapes with the reduced pinch phenomenon.

(2) As for the load-carrying capability and stiffness, the cracking load of the prefabricated columns is almost identical with that of the cast-in-situ columns. Take the fully grouted specimen 5\# for example; its yield load and ultimate load are slightly less than that of the cast-in-situ columns. Furthermore, the stiffness of the prefabricated columns degrades slower than that of the cast-in-situ columns.

(3) Based on the viscous damping coefficient and displacement ductility, the behavior of energy dissipation of the prefabricated columns is close to that of the cast-in-situ columns, indicating that the prefabricated columns have satisfactory energy-dissipating capacity.

(4) The ultimate displacement angle of the prefabricated columns is between 1/104 and 1/54, which satisfies the requirements of the code for seismic design on columns under rare earthquake [44].

\subsection{Design Recommendations}

In this section, based on the analysis of the experimental results, the following recommendations on practical seismic design pertaining to the precast concrete members connected by the grouted splice sleeve are proposed:

(1) Stirrups should be configured in the range of the sleeve height to improve the compression capacity of concrete. Furthermore, the sleeve shall be further optimized in terms of configuration, in order to prevent the grouting material from clogging and to ensure that the installation of the sleeve has no effect on the fixing of reinforcement.

(2) The interface between the column body and pedestal, including the side, top, and bottom surfaces of the prefabricated members can be roughened, and the minimum exposed height of the coarse aggregate should be specified. Moreover, the preset slot with the thickness of $20 \mathrm{~mm}$ between the column body and pedestal should be sealed by high-strength grouting material, which can effectively prevent the grout from leaking out as well as improve the load-carrying capability.

(3) Grouting material should possess high strength, high liquidity, and long initial setting time. However, the grouting material with high strength may lead to low plasticity. It is recommended to produce the modified grouting material with more significant performance according to the requirements of the corresponding regulations, on the premise that the compressive strength can attain $100 \mathrm{MPa}$ within 7 days. 


\section{Conclusions}

In this paper, the pseudo-static tests of both the precast columns using grouted splice sleeves to connect steel bars and the cast-in-situ columns have been conducted. According to the analysis and discussion of the test results in the above sections, several main conclusions are drawn as follows:

(1) The failure modes between the prefabricated columns and cast-in-situ columns are basically the same, which are both bending failure. The cracks widen visibly at the tensile edge of the concrete, and the columns fail by crushing of the concrete in the compressive zone and tensile yielding of the vertical reinforcement bars in the tensile zone. The ultimate displacement angle of the prefabricated columns are between $1 / 104$ and $1 / 54$, which satisfies the regulation in rare earthquake situations and demonstrates that the grouted splice sleeve is reliable in the connection between the prefabricated members.

(2) For the cast-in-situ columns, there is a horizontal interconnected crack in the interface between the column foot and pedestal, while for the prefabricated columns, horizontal cracks appear above the sleeve, and then develop into diagonal cracks, and finally, many cracks with large width form within the range of height of $300 \mathrm{~mm}$ above the column foot.

(3) The horizontal load-displacement curves of the prefabricated columns are basically the same with those of the cast-in-situ columns. The energy-dissipation capacity and ductility of the prefabricated columns are better than those of the cast-in-situ columns. Furthermore, the load-carrying capability of the prefabricated columns is lower than that of the cast-in-situ columns, whereas their stiffness degradation is slower than that of the cast-in-situ columns.

Acknowledgments: Financial support from the National Key Research and Development Program of China (2016YFC0701101) is highly appreciated. This work is also supported by the Fundamental Research Funds for the Central Government Supported Universities. The support from Shanghai Livable Building Science and Technology Co. Ltd., Shanghai Science and Technology Committee, and Shanghai Vanke Real Estate Co. Ltd. are also appreciated.

Author Contributions: Zheng Lu conceived the experiments and wrote the paper; Zixin Wang performed the experiments and analyzed the data; Jianbao Li proposed the method, conceived and designed the experiments, and revised the paper; Biao Huang helped to analyze the experimental data and revised the paper.

Conflicts of Interest: The authors declare no conflict of interest.

\section{References}

1. Yee, A.A. Structural and economic benefits of precast/prestressed concrete construction. PCI J. 2001, 46, 34-43. [CrossRef]

2. Yee, A.A. Social and environmental benefits of precast concrete technology. PCI J. 2001, 46, 14-19. [CrossRef]

3. Li, H.X.; Naseri Esfahani, M.; Gul, M.; Yu, H.; Mah, D.; Al-Hussein, M. Carbon footprint of panelized construction: An empirical and comparative study. In Proceedings of the 2014 Construction Research Congress: Construction in a Global Network, CRC 2014, Atlanta, GA, USA, 19-21 May 2014; American Society of Civil Engineers (ASCE): Reston, VA, USA, 2014.; pp. 494-503.

4. Lu, Z.; Chen, X.Y.; Zhang, D.C.; Dai, K.S. Experimental and analytical study on the performance of particle tuned mass dampers under seismic excitation. Earthq. Eng. Struct. Dyn. 2017, 46, 697-714. [CrossRef]

5. Lu, Z.; Wang, D.; Masri, S.F.; Lu, X. An experimental study of vibration control of wind-excited high-rise buildings using particle tuned mass dampers. Smart Struct. Syst. 2016, 18, 93-115. [CrossRef]

6. Lu, Z.; Lu, X.; Jiang, H.; Masri, S.F. Discrete element method simulation and experimental validation of particle damper system. Eng. Comput. 2014, 31, 810-823. [CrossRef]

7. Lu, Z.; Lu, X.; Lu, W.; Masri, S.F. Shaking table test of the effects of multi-unit particle dampers attached to an MDOF system under earthquake excitation. Earthq. Eng. Struct. Dyn. 2012, 41, 987-1000. [CrossRef]

8. Lu, Z.; Masri, S.F.; Lu, X.L. Parametric studies of the performance of particle dampers under harmonic excitation. Sturct. Control Health Monit. 2011, 18, 79-98. [CrossRef]

9. Lu, X.; Liu, Z.; Lu, Z. Optimization design and experimental verification of track nonlinear energy sink for vibration control under seismic excitation. Sturct. Control Health Monit. 2017. [CrossRef] 
10. Lu, Z.; Chen, X.; Li, X.; Li, P. Optimization and application of multiple tuned mass dampers in the vibration control of pedestrian bridges. Struct. Eng. Mech. 2017, 62, 55-64.

11. Lu, Z.; Wang, D.; Zhou, Y. Experimental parametric study on wind-induced vibration control of particle tuned mass damper on a benchmark high-rise building. Struct. Des. Tall Spec. Build. 2017. [CrossRef]

12. Lu, Z.; He, X.; Zhou, Y. Studies on damping behavior of vertically mixed structures with upper steel and lower concrete substructures. Struct. Des. Tall Spec. Build. 2017. [CrossRef]

13. Lu, Z.; Yang, Y.; Lu, X.; Liu, C. Preliminary study on the damping effect of a lateral damping buffer under a debris flow load. Appl. Sci. 2017, 7. [CrossRef]

14. Dai, K.; Wang, J.; Mao, R.; Lu, Z.; Chen, S.E. Experimental investigation on dynamic characterization and seismic control performance of a TLPD system. Struct. Des. Tall Spec. Build. 2017, 26. [CrossRef]

15. Lu, Z.; Chen, X.; Lu, X.; Yang, Z. Shaking table test and numerical simulation of an RC frame-core tube structure for earthquake-induced collapse. Earthq. Eng. Struct. Dyn. 2016, 45, 1537-1556. [CrossRef]

16. Ji, Y.; Zhu, F.; Li, H.X.; Al-Hussein, M. Construction industrialization in china: Current profile and the prediction. Appl. Sci. 2017, 7. [CrossRef]

17. De Boeck, L.; Verbeke, S.; Audenaert, A.; De Mesmaeker, L. Improving the energy performance of residential buildings: A literature review. Renew. Sustain. Energy Rev. 2015, 52, 960-975. [CrossRef]

18. Nejat, P.; Jomehzadeh, F.; Taheri, M.M.; Gohari, M.; Abd. Majid, M.Z. A global review of energy consumption, $\mathrm{CO}_{2}$ emissions and policy in the residential sector (with an overview of the top ten $\mathrm{CO}_{2}$ emitting countries). Renew. Sustain. Energy Rev. 2015, 43, 843-862. [CrossRef]

19. Li, D.H.W.; Yang, L.; Lam, J.C. Zero energy buildings and sustainable development implications-A review. Energy 2013, 54, 1-10. [CrossRef]

20. Dong, Y.H.; Jaillon, L.; Chu, P.; Poon, C.S. Comparing carbon emissions of precast and cast-in-situ construction methods-A case study of high-rise private building. Constr. Build. Mater. 2015, 99, 39-53. [CrossRef]

21. Won, J.-P.; Kim, H.-H.; Lee, S.-J.; Choi, S.-J. Carbon reduction of precast concrete under the marine environment. Constr. Build. Mater. 2015, 74, 118-123. [CrossRef]

22. Yee, A.A. Design considerations for precast prestressed concrete building structures in seismic areas. PCI J. 1991, 36, 40-55.

23. Yee, A.A. Splice Sleeve for Reinforcing Bars. US Patent 3540763DA, 17 November 1970.

24. Ling, J.H.; Abd. Rahman, A.B.; Ibrahim, I.S.; Abdul Hamid, Z. Tensile performance of modified hollow section splice sleeve connector under direct tensile load. In Proceedings of the 2nd Construction Industry Research Achievement International Conference (CIRAIC 2009), CIDB Convention Centre, Kuala Lumpur, Malaysia, 3-5 November 2009.

25. Anon. Mechanical connections of reinforcing bars. Concr. Int. 1983, 5, 24-35.

26. Einea, A.; Yamane, T.; Tadros, M.K. Grout-filled pipe splices for precast concrete construction. PCI J. 1995, 40, 82-93. [CrossRef]

27. Ling, J.H.; Abd. Rahman, A.B.; Ibrahim, I.S.; Hamid, Z.A. Tensile capacity of grouted splice sleeves. Eng. Struct. 2016, 111, 285-296. [CrossRef]

28. Sayadi, A.A.; Abd Rahman, A.B.; Bin Jumaat, M.Z.; Alengaram, U.J.; Ahmad, S. The relationship between interlocking mechanism and bond strength in elastic and inelastic segment of splice sleeve. Constr. Build. Mater. 2014, 55, 227-237. [CrossRef]

29. Seo, S.-Y.; Nam, B.-R.; Kim, S.-K. Tensile strength of the grout-filled head-splice-sleeve. Constr. Build. Mater. 2016, 124, 155-166. [CrossRef]

30. Henin, E.; Morcous, G. Non-proprietary bar splice sleeve for precast concrete construction. Eng. Struct. 2015, 83, 154-162. [CrossRef]

31. Hosseini, S.J.A.; Rahman, A.B.A.; Osman, M.H.; Saim, A.; Adnan, A. Bond behavior of spirally confined splice of deformed bars in grout. Constr. Build. Mater. 2015, 80, 180-194. [CrossRef]

32. Ling, J.H.; Abd. Rahman, A.B.; Ibrahim, I.S.; Abdul Hamid, Z. Behaviour of grouted pipe splice under incremental tensile load. Constr. Build. Mater. 2012, 33, 90-98. [CrossRef]

33. Rahman, A.B.A. Performance of corrugated aluminium sleeve connector under direct tensil load. In Proceedings of the 2nd Engineering Conference (EnCon08), Crowne Plaza Riverside Hotel, Kuching, Sarawak, Malaysia, 18-19 December 2008. 
34. Koushfar, K.; Rahman, A.B.A.; Ahmad, Y.; Osman, M.H. Bond behavior of the reinforcement bar in glass fiber-reinforced polymer connector. Gradjevinar 2014, 66, 301-310.

35. Sayadi, A.A.; Abd. Rahman, A.B.; Sayadi, A.; Bahmani, M.; Shahryari, L. Effective of elastic and inelastic zone on behavior of glass fiber reinforced polymer splice sleeve. Constr. Build. Mater. 2015, 80, 38-47. [CrossRef]

36. Jin, L.; Du, X.; Li, D.; Su, X. Seismic behavior of rc cantilever beams under low cyclic loading and size effect on shear strength: An experimental characterization. Eng. Struct. 2016, 122, 93-107. [CrossRef]

37. Li, W.; Li, Q. Seismic performance of L-shaped RC shear wall subjected to cyclic loading. Struct. Des. Tall Spec. Build. 2012, 21, 855-866. [CrossRef]

38. Ma, H.; Xue, J.; Zhang, X.; Luo, D. Seismic performance of steel-reinforced recycled concrete columns under low cyclic loads. Constr. Build. Mater. 2013, 48, 229-237. [CrossRef]

39. Azizinamini, A.; Kuska, S.S.B.; Brungardt, P.; Hatfield, E. Seismic behavior of square high-strength concrete columns. Struct. J. 1994, 91, 336-345.

40. John, H.T.; John, W.W. Lateral load behavior of reinforced concrete columns constructed using high-strength materials. Struct. J. 1994, 91, 605-615.

41. Sheikh, S.A.; Shah, D.V.; Khoury, S.S. Confinement of high-strength concrete columns. Struct. J. 1994, 91, 100-111.

42. Chopra, A.K. Dynamic of Structures-Theory and Applications to Earthquake Engineering, 4th ed.; Prentice Hall: Upper Saddle River, NJ, USA, 2012.

43. Li, Z.X.; Zhang, X.S.; Ding, Y. Seismic behavior of joints of prefabricated steel reinforced concrete integral frame. J. Build. Struct. 2005, 26, 32-38. (In Chinese)

44. Ministry of Housing and Urban-Rural Development of the People's Republic of China. Code for Seismic Design of Buildings (GB 50011-2010); China Building Industry Press: Beijing, China, 2010. (In Chinese)

(C) 2017 by the authors. Licensee MDPI, Basel, Switzerland. This article is an open access article distributed under the terms and conditions of the Creative Commons Attribution (CC BY) license (http:/ / creativecommons.org/licenses/by/4.0/). 